\title{
Muscle strength in patients with acromegaly at diagnosis and during long-term follow-up
}

\author{
Laila Füchtbauer', Daniel S Olsson', Bengt-Åke Bengtsson'1, Lise-Lott Norrman², \\ Katharina S Sunnerhagen ${ }^{3}$ and Gudmundur Johannsson' ${ }^{1}$ \\ 'Department of Internal Medicine and Clinical Nutrition, Institute of Medicine, Sahlgrenska Academy, University \\ of Gothenburg and Department of Endocrinology, Sahlgrenska University Hospital, Gothenburg, Sweden, \\ ${ }^{2}$ Department of Internal Medicine, Södra Älvsborgs Sjukhus, Borås, Sweden, and ${ }^{3}$ Institute of Neuroscience \\ and Physiology, Section for Clinical Neuroscience, Sahlgrenska Academy, University of Gothenburg, \\ Gothenburg, Sweden
}

\author{
Correspondence \\ should be addressed \\ to L Füchtbauer \\ Email \\ laila.fuchtbauer@vgregion.se
}

\begin{abstract}
Objective: Patients with acromegaly have decreased body fat (BF) and increased extracellular water (ECW) and muscle mass. Although there is a lack of systematic studies on muscle function, it is believed that patients with acromegaly may suffer from proximal muscle weakness despite their increased muscle mass. We studied body composition and muscle function in untreated acromegaly and after biochemical remission.

Design: Prospective observational study.

Methods: Patients with acromegaly underwent measurements of muscle strength (dynamometers) and body composition (four-compartment model) at diagnosis $(n=48), 1$ year after surgery $(n=29)$ and after long-term follow-up (median 11 years) $(n=24)$. Results were compared to healthy subjects.

Results: Untreated patients had increased body cell mass $(113 \pm 9 \%$ of predicted) and ECW $(110 \pm 20 \%)$ and decreased BF $(67 \pm 7.6 \%)$. At one-year follow-up, serum concentration of IGF-I was reduced and body composition had normalized. At baseline, isometric muscle strength in knee flexors and extensors was normal and concentric strength was modestly increased whereas grip strength and endurance was reduced. After one year, muscle strength was normal in both patients with still active disease and patients in remission. At long-term follow-up, all patients were in remission. Most muscle function tests remained normal, but isometric flexion and the fatigue index were increased to $153 \pm 42 \%$ and $139 \pm 28 \%$ of predicted values, respectively.

Conclusions: Patients with untreated acromegaly had increased body cell mass and normal or modestly increased proximal muscle strength, whereas their grip strength was reduced. After biochemical improvement and remission, body composition was normalized, hand grip strength was increased, whereas proximal muscle fatigue increased.
\end{abstract}

\section{Introduction}

In acromegaly, the excess growth hormone (GH) and elevated serum concentration of insulin-like growth factor I (IGF-I) are associated with excess mortality, mainly due to cardiovascular diseases, and there is evidence that normalization of GH and IGF-I also normalize the risk of death (1). As the disease develops slowly with unspecific symptoms in the beginning, time to diagnosis can be delayed several years, at which time several comorbidities may have developed. Hypertension (40\%), other neoplasms (30\%), hypopituitarism (22\%), diabetes mellitus (17\%), arthropathies (15\%) and sleep disorders (14\%) are the most frequent comorbidities in Swedish patients with acromegaly (2). Body composition is also altered with a decrease of total body fat (BF) more specifically truncal fat www.eje-online.org DOI: 10.1530/EJE-17-0120
() 2017 European Society of Endocrinology Printed in Great Britain
Published by Bioscientifica Ltd. 
mass (3) and an increase in skeletal muscle mass (4) and total body water (TBW), mainly extracellular water (ECW) (5). These changes are associated with the severity of the disease, serum GH and IGF-I levels, and are normalized after successful treatment (6).

Despite increased skeletal muscle mass, weakness especially in proximal muscles has been described in patients with active acromegaly. However, studies on this topic have been few with conflicting results and limited by small sample size, lack of a control group and inadequate methodology. Early studies in the 1970s reported mild muscle weakness tested manually at physical examination, elevated creatinine kinases and myopathic patterns on electromyography (EMG) in about $50 \%$ of patients with active disease $(7,8)$. Later studies have either relied on self-reported muscle weakness or case reports showing proximal muscle weakness, myopathic patterns on EMG and variably elevated creatinine kinase levels. More recent studies measured muscle strength in patients with acromegaly and found in both younger (9) and older (10) patients decreased hand grip strength, decreased peak torque and maximum work repetition in knee extension and flexion. Both studies used a crosssectional approach, including various degrees of biochemical remission (9).

Our aim was therefore to perform a longitudinal study of muscle function and body composition at diagnosis of acromegaly, one year after treatment and after longterm remission.

\section{Subjects and methods}

\section{Subjects}

Recruitment of 48 consecutive patients with acromegaly was done at the Sahlgrenska University Hospital between 1990 and 2005. Acromegaly was diagnosed by the presence of clinical features, IGF-I levels above the ageadjusted upper limit of normal (ULN), GH nadir $>1 \mu \mathrm{g} / \mathrm{L}$ after oral glucose tolerance test or GH day curve with a minimum value $>1 \mu \mathrm{g} / \mathrm{L}$ in the presence of a pituitary adenoma. One patient was excluded due to heart failure, and in one patient, handgrip data were excluded because of paresis due to stroke. Osteoarthritis, musculoskeletal pain and history of carpal tunnel syndrome were noted but not considered exclusion criteria. Clinical characteristics are summarized in Table 1. At follow-up, patients performed GH day curve, oral glucose tolerance test and serum IGF-I measurements. Patients were
Table 1 Clinical characteristics, muscle function and body composition for 48 untreated patients with acromegaly at the time of diagnosis.

\begin{tabular}{|c|c|c|}
\hline Variable & $\begin{array}{l}\text { Mean of absolute } \\
\text { values } \pm \text { s.D. }\end{array}$ & $\begin{array}{l}\text { Relative to reference } \\
\text { population }\end{array}$ \\
\hline \multicolumn{3}{|l|}{$\overline{\text { Clinical characteristics }}$} \\
\hline $\begin{array}{l}\text { No. of patients } \\
\text { (men/women) }\end{array}$ & $48(28 / 20)$ & \\
\hline $\begin{array}{l}\text { Age in years } \\
\text { (range) }\end{array}$ & $46.4(23-74)$ & \\
\hline $\begin{array}{l}\text { Microadenoma/ } \\
\text { macroadenoma }\end{array}$ & $10 / 38$ & \\
\hline Treatment & Surgery (47);Oct(1) & \\
\hline IGF-I times ULN & $2.74 \pm 1.00$ & \\
\hline Weight $(\mathrm{kg})$ & $87.1 \pm 15.3$ & \\
\hline Height $(\mathrm{cm})$ & $177.6 \pm 10.5$ & \\
\hline BMI $\left(\mathrm{kg} / \mathrm{m}^{2}\right)$ & $27.5 \pm 3.9$ & \\
\hline Diabetes & 4 & \\
\hline $\mathrm{SBP}(\mathrm{mmHg})$ & $141.7 \pm 19.2$ & \\
\hline $\mathrm{DBP}(\mathrm{mmHg})$ & $84.4 \pm 9.9$ & \\
\hline $\begin{array}{l}\text { Ischaemic heart } \\
\text { disease }\end{array}$ & 3 & \\
\hline $\begin{array}{l}\text { Hormone } \\
\text { insufficiency }\end{array}$ & $A(2) ; T(6) ; G_{T}(4) ; G_{E}(2)$ & \\
\hline $\begin{array}{l}\text { Hormone } \\
\text { replacement }\end{array}$ & $A(2) ; T(4) ; G_{T}(0) ; G_{E}(0)$ & \\
\hline \multicolumn{3}{|l|}{ Knee extension } \\
\hline Isometric (Nm) & $199 \pm 61$ & 1.00 (Cl: 0.93-1.07) \\
\hline $\begin{array}{l}\text { Concentric 60/s } \\
(\mathrm{Nm})\end{array}$ & $170 \pm 51$ & 1.10 (Cl: $1.03-1.17)$ \\
\hline $\begin{array}{l}\text { Concentric 180/s } \\
(\mathrm{Nm})\end{array}$ & $118 \pm 35$ & 1.09 (Cl: 1.02-1.16) \\
\hline \multicolumn{3}{|l|}{ Knee flexion } \\
\hline Isometric (Nm) & $81 \pm 31$ & 1.03 (Cl: 0.95-1.11) \\
\hline $\begin{array}{l}\text { Concentric 60/s } \\
(\mathrm{Nm})\end{array}$ & $90 \pm 31$ & 1.18 (CI: $1.10-1.26)$ \\
\hline $\begin{array}{l}\text { Concentric 180/s } \\
(\mathrm{Nm})\end{array}$ & $61 \pm 22$ & 1.08 (Cl: $1.00-1.17)$ \\
\hline Fatigue index (\%) & $41 \pm 13$ & 1.10 (Cl: 0.99-1.21) \\
\hline \multicolumn{3}{|c|}{ Hand grip strength, right } \\
\hline Peak (N) & $386 \pm 135$ & 0.89 (Cl: $0.83-0.95)$ \\
\hline Average 10s $(\mathrm{N})$ & $337 \pm 120$ & 0.86 (Cl: $0.80-0.92)$ \\
\hline \multicolumn{3}{|c|}{ Hand grip strength, left } \\
\hline Peak (N) & $355 \pm 114$ & 0.89 (Cl: $0.83-0.95)$ \\
\hline Average 10s (N) & $312 \pm 103$ & 0.87 (Cl: $0.80-0.94)$ \\
\hline \multicolumn{3}{|l|}{ Body composition } \\
\hline $\mathrm{BF}(\mathrm{kg})$ & $17.1 \pm 10.2$ & 0.67 (Cl: $0.59-0.75)$ \\
\hline BCM $(\mathrm{kg})$ & $35.8 \pm 7.9$ & 1.13 (Cl: $1.10-1.16)$ \\
\hline $\mathrm{ECW}(\mathrm{kg})$ & $25.8 \pm 5.7$ & 1.10 (Cl: $1.04-1.16)$ \\
\hline
\end{tabular}

A, glucocorticoids; $\mathrm{Cl}, 95 \%$ confidence interval; DBP, diastolic blood pressure; $\mathrm{G}_{\mathrm{E}}$, oestrogen; $\mathrm{G}_{\mathrm{T}}$, testosterone; Oct, octreotide; $\mathrm{SBP}$, systolic blood pressure; S.D., standard deviation; T, thyroid hormone; ULN, upper limit of normal.

considered to have controlled disease, if two or more of these tests were normal.

\section{Study protocol}

This study was a prospective observational study of patients with acromegaly with repeated measurements 
Table 2 Clinical characteristics, muscle function relative to reference population and body composition for 29 patients at diagnosis and after a median of 1 year for patients with controlled and uncontrolled disease.

\begin{tabular}{|c|c|c|c|c|c|c|}
\hline \multirow[b]{2}{*}{ Variable } & \multicolumn{2}{|c|}{ Controlled disease } & \multirow[b]{2}{*}{$P$ value } & \multicolumn{2}{|c|}{ Uncontrolled disease } & \multirow[b]{2}{*}{$P$ value } \\
\hline & At diagnosis & 1-year follow-up & & At diagnosis & 1-year follow-up & \\
\hline \multicolumn{7}{|l|}{ Clinical characteristics } \\
\hline $\begin{array}{l}\text { No. of patients; men/ } \\
\text { women }\end{array}$ & $23(17 / 6)$ & & & $6(3 / 3)$ & & \\
\hline $\begin{array}{l}\text { Microadenoma/ } \\
\text { macroadenoma }\end{array}$ & $6 / 17$ & & & $1 / 5$ & & \\
\hline Age in years (range) & $46.3(23-67)$ & $47.8(24-69)$ & & $46.5(29-75)$ & $48.4(32-77)$ & \\
\hline Treatment & Surgery (23) & $\operatorname{Bro}(1) ; \operatorname{STR}(1)$ & & Surgery (6) & $\operatorname{STR}(1)$ & \\
\hline $\begin{array}{l}\text { Time from 1st } \\
\text { treatment (years) }\end{array}$ & - & $1.1 \pm 0.3$ & & - & $1.6 \pm 0.8$ & \\
\hline IGF-I times ULN \pm S.D. & $2.97 \pm 1.2$ & $0.71 \pm 0.27$ & $<0.0001$ & $2.66 \pm 0.63$ & $1.17 \pm 0.79$ & 0.0032 \\
\hline Weight $(\mathrm{kg}) \pm$ S.D. & $87.9 \pm 15.1$ & $89.0 \pm 15.0$ & 0.41 & $89.4 \pm 21.3$ & $87.4 \pm 83.6$ & 0.59 \\
\hline Height $(\mathrm{cm}) \pm$ S.D. & $180.1 \pm 9.3$ & $179.1 \pm 9.2$ & 0.0012 & $175.1 \pm 10.6$ & $173.7 \pm 10.2$ & 0.048 \\
\hline $\mathrm{BMI}\left(\mathrm{kg} / \mathrm{m}^{2}\right) \pm$ S.D. & $27.1 \pm 4.1$ & $27.6 \pm 4.7$ & 0.20 & $29.0 \pm 5.6$ & $28.8 \pm 6.6$ & 0.84 \\
\hline Diabetes & 1 & 1 & & 0 & 0 & \\
\hline SBP $(m m H g) \pm$ S.D. & $142 \pm 21$ & $131.8 \pm 15.1$ & 0.071 & $142 \pm 12$ & $130 \pm 14.1$ & 0.27 \\
\hline $\begin{array}{l}\mathrm{DBP}(\mathrm{mmHg}) \pm \text { s.D. } \\
\text { Ischaemic heart } \\
\text { disease }\end{array}$ & $\frac{83 \pm 10}{1}$ & $81.1 \pm 13.2$ & 0.39 & $\begin{array}{c}86 \pm 9 \\
0\end{array}$ & $\begin{array}{c}76.3 \pm 7.5 \\
0\end{array}$ & 0.22 \\
\hline Hormone insufficiency & $A(1) ; T(2) ; G_{T}(1) ; G_{E}(1)$ & $\mathrm{T}(2) ; \mathrm{G}_{\mathrm{T}}(4) ; \mathrm{G}_{\mathrm{E}}(1) ; \mathrm{ADH}(1)$ & & $\mathrm{T}(1) ; \mathrm{G}_{\mathrm{T}}(1)$ & 0 & \\
\hline Hormone replacement & $A(1) ; T(2) ; G_{T}(0) ; G_{E}(1)$ & $\mathrm{T}(1) ; \mathrm{G}_{\mathrm{T}}(3) ; \mathrm{G}_{\mathrm{E}}(1) ; \mathrm{ADH}(1)$ & & 0 & 0 & \\
\hline \multicolumn{7}{|c|}{ Knee extension } \\
\hline Isometric & $1.00(\mathrm{Cl}: 0.90-1.10)$ & 1.00 (Cl: 0.91-1.09) & 0.6 & 1.09 (Cl: 0.84-1.34) & 1.00 (Cl: 0.84-1.17) & $>0.05$ \\
\hline Concentric 60/s & $1.11(\mathrm{Cl}: 1.02-1.21)$ & 1.07 (Cl: 0.99-1.15) & 0.17 & 1.09 (Cl: 0.83-1.35) & 0.99 (Cl: 0.76-1.22) & $>0.05$ \\
\hline Concentric $180 / \mathrm{s}$ & $1.11(\mathrm{Cl}: 1.01-1.21)$ & 1.08 (Cl: 0.99-1.17) & 0.12 & $1.04(\mathrm{Cl}: 0.80-1.28)$ & 1.06 (Cl: 0.84-1.28) & $>0.05$ \\
\hline \multicolumn{7}{|l|}{ Knee flexion } \\
\hline Isometric & $0.96(\mathrm{Cl}: 0.86-1.06)$ & $0.95(\mathrm{Cl}: 0.85-1.05)$ & 0.72 & $1.11(\mathrm{Cl}: 0.97-1.25)$ & 0.99 (Cl: 0.81-1.17) & $>0.05$ \\
\hline Concentric $60 / \mathrm{s}$ & $1.16(\mathrm{Cl}: 1.06-1.26)$ & $1.13(\mathrm{Cl}: 1.04-1.22)$ & 0.44 & $1.21(\mathrm{Cl}: 1.02-1.40)$ & 1.11 (Cl: 0.97-1.25) & $>0.05$ \\
\hline Concentric 180/s & $1.10(\mathrm{Cl}: 1.00-1.21)$ & 1.08 (Cl: 0.98-1.18) & 0.38 & $1.12(\mathrm{Cl}: 0.87-1.37)$ & $1.02(\mathrm{Cl}: 0.80-1.24)$ & $>0.05$ \\
\hline Fatigue index (\%) & $0.93(\mathrm{Cl}: 0.84-1.02)$ & 1.00 (Cl: 0.86-1.14) & 0.76 & 1.24 (Cl: 0.91-1.57) & 1.15 (Cl: 0.73-1.57) & $>0.05$ \\
\hline \multicolumn{7}{|c|}{ Hand grip strength, right } \\
\hline Peak & 0.85 (Cl: 0.77-0.94) & 0.92 (Cl: 0.84-1.00) & 0.0053 & $0.98(\mathrm{Cl}: 0.88-1.08)$ & 1.04 (Cl: 0.89-1.19) & $>0.05$ \\
\hline Average $10 \mathrm{~s}$ & $0.81(\mathrm{Cl}: 0.72-0.90)$ & $0.92(\mathrm{Cl}: 0.83-1.01)$ & 0.001 & 1.00 (Cl: 0.87-1.13) & 1.03 (Cl: 0.89-1.17) & $>0.05$ \\
\hline \multicolumn{7}{|c|}{ Hand grip strength, left } \\
\hline Peak & $0.81(\mathrm{Cl}: 0.72-0.90)$ & 0.93 (Cl: 0.85-1.01) & 0.0024 & 1.05 (Cl: 0.87-1.23) & 1.08 (Cl: 0.89-1.27) & $>0.05$ \\
\hline Average $10 \mathrm{~s}$ & $0.81(\mathrm{Cl}: 0.72-0.91)$ & 0.93 (Cl: 0.84-1.02) & 0.0021 & 1.07 (Cl: 0.87-1.27) & 1.07 (Cl: 0.88-1.26) & $>0.05$ \\
\hline \multicolumn{7}{|l|}{ Body composition } \\
\hline$B F(k g) \pm S . D$. & $16.0 \pm 11.0$ & $20.7 \pm 11.4$ & & $13.4 \pm 10.6$ & $22.1 \pm 14.0$ & \\
\hline $\begin{array}{l}\text { BF (relative to } \\
\text { predicted) }\end{array}$ & $0.66(\mathrm{Cl}: 0.55-0.77)$ & 0.84 (Cl: $0.74-0.92)$ & 0.016 & 0.49 (Cl: $0.48-0.67)$ & 0.84 (Cl: $0.66-1.02)$ & $\leq 0.05^{*}$ \\
\hline$B C M(k g) \pm S . D$. & $37.1 \pm 7.3$ & $35.0 \pm 6.7$ & & $35.5 \pm 8.9$ & $32.1 \pm 8.4$ & \\
\hline $\begin{array}{l}\text { BCM (relative to } \\
\text { predicted) }\end{array}$ & 1.12 (Cl: 1.08-1.16) & $1.06(\mathrm{Cl}: 1.02-1.10)$ & 0.0014 & 1.18 (Cl: $1.12-1.23)$ & 1.07 (Cl: $1.00-1.14)$ & $\leq 0.05^{*}$ \\
\hline $\mathrm{ECW}(\mathrm{kg}) \pm$ S.D. & $26.5 \pm 6.1$ & $24.3 \pm 3.6$ & & $28.1 \pm 5.1$ & $23.3 \pm 4.1$ & \\
\hline $\begin{array}{l}\text { ECW (relative to } \\
\text { predicted) }\end{array}$ & 1.07 (Cl: 0.98-1.16) & 1.00 (Cl: 0.93-1.07) & 0.15 & 1.27 (Cl: 1.07-1.47) & 1.08 (Cl: 0.88-1.28) & $>0.05$ \\
\hline
\end{tabular}

*Because of the low sample size, a precise $P$ value could not be determined using the Wilcoxon signed-rank test. However, significance was reached at an alpha 0.05 level.

A, glucocorticoids; $A D H$, antidiuretic hormone; Bro, bromocriptine; $\mathrm{Cl}, 95 \%$ confidence interval; $D B P$, diastolic blood pressure; $G_{E}$, oestrogen; $G_{T}$, testosterone; Oct, Octreotide; SBP, systolic blood pressure; s.D., standard deviation; STR, stereotactic radiotherapy; T, thyroid hormone; ULN, upper limit of normal.

of muscle strength and body composition. Patients were included at the time of diagnosis when they performed physical and biochemical examinations, muscle tests and measurement of body composition before any type of intervention occurred. They were then treated according to best clinical practice with either surgery or medical treatment or both. Some patients received radiotherapy at a later time. If necessary, patients received replacement therapy with glucocorticoids, sex steroids, GH or thyroid hormone (Tables 2 and 3). Tests were repeated after a median (range) of 1 (1-3) year and 11 (3-20) years after initial treatment. After a median follow-up of 1 year 
and 11 years, three and eight men received testosterone replacement, respectively.

\section{Reference populations}

As muscle function is highly dependent on age and gender, each muscle test result for each patient was compared to the mean result of that same test from $\geq 6$ (range 6-27) healthy age and gender-matched controls. The controls were part of a reference population of 144 healthy men and women randomly selected from the population census from the city of Gothenburg using the same methodology and in the same laboratory as in this study (11). The reference population formed 10-year cohorts for the ages 40-49, 50-59, 60-69 and
70-79 for each gender. Thus, each patient was matched for age and gender and given a predicted value from the reference group. Patients younger than 40 years of age ( 8 men and 7 women) were given predicted values from the 40-49-year cohort. The resulting observed/predicted ratios were then used in the statistical analysis.

Body composition is also highly dependent on age and gender and the result from each patient was therefore compared to predicted values derived from healthy subjects in an algorithm including age, gender and body mass index (BMI). This algorithm was based on measurements of total body potassium (TBK) and TBW in a cohort of 476 healthy individuals from the city of

Table 3 Clinical characteristics and muscle function relative to reference population at diagnosis and after a median of 11 years for 24 patients with acromegaly.

\begin{tabular}{l} 
Variable \\
\hline Clinical characteristics \\
No. of patient (men/women) \\
Microadenoma/macroadenoma \\
Age in years (range) \\
Treatment \\
Time from 1st treatment (years) \\
IGF-I times ULN \pm s.D. \\
Weight $(\mathrm{kg}) \pm$ s.D. \\
Height $(\mathrm{cm}) \pm$ S.D. \\
BMI (kg/m $\left.{ }^{2}\right) \pm$ s.D. \\
Diabetes \\
SBP (mmHg) \pm S.D. \\
DBP (mmHg) \pm s.D. \\
Ischaemic heart disease \\
Hormone insufficiency \\
Hormone replacement \\
Knee extension \\
Isometric \\
Concentric 60/s \\
Concentric 180/s \\
Knee flexion \\
Isometric \\
Concentric 60/s \\
Concentric 180/s \\
Fatigue index $(\%)$ \\
Hand grip strength, right \\
Peak \\
Average 10 s \\
Hand grip strength, left \\
Peak \\
Average 10 s
\end{tabular}

\begin{tabular}{c}
\hline At diagnosis \\
\hline $24(14 / 10)$ \\
$4 / 20$ \\
$41.3(23-63)$ \\
Surgery $(24)$ \\
- \\
$3.06 \pm 0.94$ \\
$89.2 \pm 17$ \\
$179.4 \pm 11$ \\
$27.6 \pm 4$ \\
1 \\
$138.8 \pm 15$ \\
$83.3 \pm 11$ \\
0 \\
$\mathrm{~A}(1) ; \mathrm{T}(3) ; \mathrm{G}_{\mathrm{T}}(1) ; \mathrm{G}_{\mathrm{E}}(1)$ \\
$\mathrm{A}(1) ; \mathrm{T}(3) ; \mathrm{G}_{\mathrm{T}}(0) ; \mathrm{G}_{\mathrm{E}}(0)$ \\
\\
$1.04(\mathrm{Cl}: 0.94-1.15)$ \\
$1.15(\mathrm{Cl}: 1.06-1.24)$ \\
$1.15(\mathrm{Cl}: 1.05-1.25)$ \\
\\
$1.03(\mathrm{Cl}: 0.94-1.12)$ \\
$1.19(\mathrm{Cl}: 1.10-1.28)$ \\
$1.16(\mathrm{Cl}: 1.06-1.26)$ \\
$1.00(\mathrm{Cl}: 0.88-1.12)$ \\
\\
$0.91(\mathrm{Cl}: 0.85-0.97)$ \\
$0.89(\mathrm{Cl}: 0.83-0.96)$ \\
$0.91(\mathrm{Cl}: 0.82-1.00)$ \\
$0.90(\mathrm{Cl}: 0.80-1.00)$ \\
\\
\\
\\
\end{tabular}

11-year follow-up
P-value

$\begin{array}{cc}53.7 \text { (30-78) } & \\ \text { Re-op(2);STR(4);Oct(6); } \operatorname{Lan}(3) ; \operatorname{Bro}(1) ; \operatorname{Cab}(1) ; \operatorname{Peg}(1) & \\ 11.8 \pm 5.4 & \\ 0.73 \pm 0.23^{*} & <0.0001 \\ 92.0 \pm 20.9 & 0.30 \\ 177.4 \pm 9.9 & 0.00040 \\ 28.5 \pm 5.1 & 0.070 \\ 3 & \\ 127.5 \pm 12.7 & 0.014 \\ 75.3 \pm 11.6 & 0.0079\end{array}$
$A(1) ; T(5) ; G_{T}(9) ; G_{E}(2) ; G H(1)$ $A(1) ; T(5) ; G_{T}(8) ; G_{E}(2) ; G H(1)$

\begin{tabular}{|c|c|}
\hline 0.97 (Cl: 0.85-1.09) & 0.16 \\
\hline 1.10 (Cl: 0.99-1.21) & 0.37 \\
\hline 1.04 (Cl: 0.92-1.16) & 0.035 \\
\hline $1.54(\mathrm{Cl}: 1.37-1.71)$ & $<0.0001$ \\
\hline 1.35 (Cl: 1.16-1.54) & 0.054 \\
\hline 1.12 (Cl: 0.94-1.30) & 0.79 \\
\hline 1.39 (Cl: $1.28-1.50)$ & 0.0013 \\
\hline 0.98 (Cl: 0.91-1.05) & 0.018 \\
\hline 0.95 (Cl: 0.85-1.03) & 0.091 \\
\hline 1.00 (Cl: 0.92-1.08) & 0.019 \\
\hline 0.96 (Cl: 0.88-1.04) & 0.19 \\
\hline
\end{tabular}

*One patient was not considered in remission at time of the test. Her IGF-I was $1.55 \mathrm{ULN}$ and she was under treatment with Lanreotide. A, glucocorticoids; Bro, bromocriptine; Cab, cabergoline; Cl, $95 \%$ confidence interval; DBP, diastolic blood pressure; $\mathrm{G}_{\mathrm{E}}$, oestrogen; $\mathrm{GH}$, growth hormone; $\mathrm{G}_{\mathrm{T}}$, testosterone; Lan, lanreotide; Oct, octreotide; Peg, pegvisomant; Re-op, re-operated; SBP, systolic blood pressure; s.D., standard deviation; STR, stereotactic radiotherapy; T, thyroid hormone; ULN, upper limit of normal. 
Gothenburg, using the same methodology and laboratory as in this study (12).

\section{Ethical considerations}

Informed consent was obtained from all patients. The study was approved by the Regional Ethics Review Board in Gothenburg, Sweden (Dnr. 208-04).

\section{Biochemical analysis}

The technique for measuring serum IGF-I levels changed during the study period. The individual results were therefore compared to the age- and gender-matched reference interval supplied by the producer to acquire a percentage of the ULN. Before October 2002, serum IGF-I levels were measured using a radioimmunoassay after acid-ethanol extraction (Nichols Institute Diagnostics, San Juan Capistrano, CA, USA). From October 2002 to September 2006, serum IGF-I was measured using a chemiluminescent immunoassay (Advantage, Nichols Institute Diagnostics). After September 2006, Immulite automated chemiluminescence system from Siemens was used (Immulite2500/200Xpi, Siemens Medical Solutions Diagnostics). The method for measuring serum human GH also changed during the study period. Before 1994, an immunoradiometric assay was used (Pharmacia Diagnostic AB, Sweden). Between 1994 and 2008, an immunofluorometric assay was used (DELFIA, Wallac, Sweden). After 2008, a one-step immunoenzymatic method was used (Access2, Beckman Coulter, Bromma).

\section{Measurements of muscle function}

Muscle performance of knee extensors and flexors was measured on a Kin-Com (Chattanooga Group Inc., PO Box 489, Hixson, TN, USA) dynamometer until 2001 and subsequently on a Biodex Multi-Joint System 3 PRO dynamometer (Biodex Medical Systems, Shirley, NY, USA), as described previously (11). Before switching dynamometer, 10 healthy persons were tested in a random order on the two dynamometers with a standard test of both lower extremities in isometric and isokinetic set-ups with similar results. Briefly, after a 5-min warm-up on a bicycle ergonometer, subjects were seated on the dynamometer and the different tests were performed on their right leg separated by $2-2.5$ min rests. One patient was tested on the left leg because of severe arthritis on the right side. Peak isometric strength was measured at a $60^{\circ}$ knee angle during extension and flexion. Maximal concentric (isokinetic) strength was measured at a velocity of $60^{\circ} / \mathrm{s}$ and $180^{\circ} \mathrm{s}$ for extension and flexion. Isokinetic endurance was evaluated as the fatigue index, the reduction in peak torque at an angular velocity of $180^{\circ} / \mathrm{s}$ between the first and the last three knee extensions in a series of 50 maximal concentric muscle actions. Maximum grip force and the mean value of a 10-s sustained grip for both hands were measured on a Grippit ( $\mathrm{AB}$ Detector, Göteborg, Sweden) as described earlier (13).

\section{Measurement of body composition}

Body composition was estimated using a fourcompartment model where body cell mass (BCM), ECW, $\mathrm{BF}$ and fat-free extracellular solids are calculated from measurements of TBW and TBK. TBW was measured using an isotope dilution technique with tritiated water as tracer (12). TBK was determined by counting the gamma radiation from the naturally present radionuclide ${ }^{40} \mathrm{~K}$, which is a constant fraction of all natural potassium, in a high-sensitivity whole-body counter as described earlier (12).

\section{Statistical analysis}

Descriptive results are shown as means (s.e.m.). For comparison of test results to the reference populations and between base line and follow-up, individual observed/predicted value ratios were calculated for each test person and result using the above-mentioned reference populations. The 95\% confidence interval (CI) was calculated. For the follow-up analyses, observed/ predicted ratios were then compared using a two-tailed Wilcoxon Signed-Rank test, and $P$ values $<0.05$ were considered significant. Baseline results between groups were compared with a two-tailed homoscedastic $t$-test if they were normally distributed and otherwise with a two-tailed Mann-Whitney $U$-test. The software IBM SPSS (version 21; SPSS Institute) was used to perform the analyses in the study.

\section{Results}

\section{Baseline evaluation}

Results from muscle tests, clinical characteristics and body composition at diagnosis are shown in Table 1. Concentric muscle strength of the knee extensors and flexors was 
A

\begin{tabular}{|c|c|c|c|c|c|c|}
\hline Muscle test & Baseline & $95 \% \mathrm{Cl}$ & 1 year follow-up & $95 \% \mathrm{Cl}$ & 11 year follow-up & $\mathbf{9 5} \% \mathrm{Cl}$ \\
\hline Knee extension Isometric & & $1.00(0.92,1.07)$ & & $1.00(0.92,1.08)$ & 1 & $0.97(0.85,1.09)$ \\
\hline Knee extension Concentric $60 \mathrm{deg} / \mathrm{s}$ & & $1.10(1.03,1.17)$ & & $1.05(0.97,1.13)$ & & $1.10(0.99,1.21)$ \\
\hline Knee extension Concentric $180 \mathrm{deg} / \mathrm{s}$ & & $1.09(1.02,1.16)$ & & $1.07(0.99,1.15)$ & & $1.04(0.92,1.16)$ \\
\hline Knee flexion Isometric & & $1.03(0.95,1.11)$ & & $0.96(0.87,1.05)$ & & $1.54(1.37,1.71)$ \\
\hline Knee flexion Concentric $60 \mathrm{deg} / \mathrm{s}$ & & $1.18(1.10,1.26)$ & & $1.13(1.06,1.20)$ & & $1.35(1.16,1.54)$ \\
\hline Knee flexion Concentric $180 \mathrm{deg} / \mathrm{s}$ & & $1.08(1.00,1.17)$ & & $1.07(0.98,1.16)$ & & $1.12(0.94,1.30)$ \\
\hline Fatigue index (\%) & & $1.10(0.99,1.21)$ & & $1.04(0.89,1.19)$ & $\rightarrow$ & $1.39(1.28,1.50)$ \\
\hline & 1 & & 0.75 & & 0.751 & \\
\hline
\end{tabular}

B

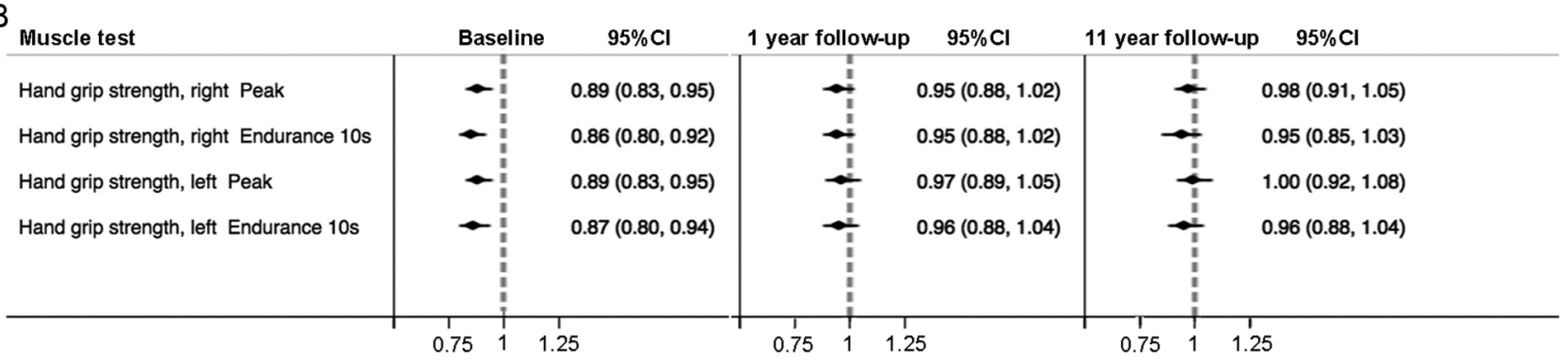

\section{Figure 1}

Mean and $95 \%$ confidence intervals of (A) proximal muscle strength and (B) hand grip strength at diagnosis $(n=48), 1$ year after treatment $(n=29)$ and after long-term remission $(n=24)$ for patients with acromegaly relative to healthy controls.

slightly increased in patients with acromegaly compared to the reference population as reflected by CIs of observed/ predicted values above 1.00, while isometric strength and the fatigue index were not increased (Fig. 1A). However, the patients had weaker peak hand grip strength and average grip strength over $10 \mathrm{~s}$ in both hands at baseline compared to the reference population (the CIs for these ratios were below 1.00) (Fig. 1B). The patients had reduced BF (CI: 0.59-0.75) and increased BCM (CI: 1.10-1.16) and ECW (CI: 1.04-1.16).

\section{One-year follow-up in biochemically controlled and uncontrolled patients}

Clinical characteristics, muscle function and body composition of 29 patients with acromegaly at diagnosis and after a median of 12 months after initial treatment are shown in Table 2 (controlled: $n=23$; uncontrolled: $n=6$ ). At diagnosis, there was no significant difference in age $(P=0.97)$, age-adjusted serum IGF-I levels $(P=0.56)$, length $(P=0.26)$, body weight $(P=0.85)$, blood pressure (systolic $P=0.97$, diastolic $P=0.58)$, BF $(P=0.16)$, BCM $(P=0.22)$ or ECW $(P=0.062)$ between patients whose disease was controlled and those with uncontrolled disease after one year. At follow-up, both groups had a significant reduction in serum IGF-I levels (controlled disease $P<0.0001$; uncontrolled disease $P=0.0032$ ) compared to baseline.

Muscle function tests at baseline were comparable between patients with controlled and uncontrolled disease with the exception of peak hand grip strength $(P=0.046)$ and average grip strength over $10 \mathrm{~s}$ of the left hand $(P=0.042)$, where patients with controlled disease at follow-up performed worse than those with uncontrolled disease. The frequency of carpal tunnel syndrome (controlled: 3/23; uncontrolled: 1/6) or any other comorbidity was similar in the two groups. At follow-up, strength and endurance in the proximal muscle groups remained unchanged, while hand grip strength and endurance in both hands had improved significantly to normal levels in patients in remission (Fig. 1B and Table 2). Hence, one year after treatment, both groups had normal muscle function in the proximal and distal muscle groups.

In most muscle function tests, there were no differences between the genders (for values relative to their predicted values). For a few tests, however, women's relative values were higher compared to men (at baseline concentric extension at $180^{\circ} / \mathrm{s} \quad(P=0.019)$, at 1 -year follow-up concentric extension at $180^{\circ} / \mathrm{s}(P=0.038)$ and left hand strength $(P=0.021)$ and endurance $(P=0.037)$. 
There was a significant reduction of BCM to the predicted level in both groups (controlled disease $P=0.0014$; uncontrolled disease $P<0.05)$. Furthermore, $\mathrm{BF}$ was significantly increased (controlled disease $P=0.016$; uncontrolled disease $P<0.05$ ), but did not reach normal reference levels as reflected by the CI. There was a trend towards decreased ECW that did not reach statistical significance unless pooling the data from patients with controlled and uncontrolled disease $(P=0.016$, data not shown).

\section{Follow-up after 11 years}

After a median follow-up of 11 (range 3-20) years after primary treatment, muscle function testing was repeated in 24 patients. Clinical characteristics and test results are shown in Table 3. Eleven patients had received additional treatment after primary surgery, and 13 patients had developed pituitary insufficiencies that were replaced. Mean serum IGF-I levels were decreased from diagnosis $(P<0.0001)$. Also, both diastolic $(P=0.0079)$ and systolic $(P=0.014)$ blood pressure had decreased, which was not seen at the 1-year follow-up.

Isometric extension of the knee and concentric extension at $60^{\circ} / \mathrm{s}$ remained comparable to the reference population throughout the period of follow-up (Table 3), while faster concentric extension at $180^{\circ} / \mathrm{s}$ had decreased $(P=0.035)$. Endurance was reduced as reflected in an increased fatigue index $(P=0.0013)$. The patients had, however, improved their isometric knee flexor strength to a level higher than the reference population $(P<0.0001)$. No change in concentric knee flexion was noted (Fig. 1A and Table 3). Maximum grip strength, which already had normalized at short-term follow-up, remained normal at long-term follow-up.

\section{Discussion}

The present study has shown that the increase in BCM and ECW and decrease in BF at diagnosis in patients with acromegaly are normalized after a median follow-up of 12 months after treatment. We found that concentric knee flexion and extension were slightly increased at diagnosis, while isometric strength and the fatigue index did not differ from a healthy reference population. One year after treatment, proximal muscle function was comparable to the reference population. On the other hand, upper extremity distal muscle function was weaker in patients with active acromegaly, but normalized after treatment.
After many years in remission, most muscle function tests were normal. However, isometric knee flexion was higher than normal, whereas endurance had decreased.

The changes observed in body composition in our study are in line with what has been observed in previous studies in patients with acromegaly using various methods $(3,4,5,14,15)$. It has been discussed whether the observed changes in BCM and muscle volume could be due to changes in body water, as widely used methods such as DXA and bioimpedance analysis cannot discriminate between water and protein or are based on regression equations derived from densitometry studies in normal populations (16). The direct potassium counting method, used in the current study, circumvents these problems and may thus be regarded the gold standard for evaluating BCM. We showed a decrease in BCM one year after treatment. Other studies using bioimpedance analysis and computed tomography have shown a reduction in BCM/muscle volume and increase in adipose tissue/adipose tissue volume as early as 3 months (17) and 1 year (4) after treatment, respectively.

Proximal muscle strength measured in the leg of patients with acromegaly at diagnosis was slightly increased or comparable to healthy controls and essentially remained so after treatment. To the best of our knowledge, proximal muscle strength of untreated patients with acromegaly has never been tested quantitatively before. The discrepancy between our findings of normal muscle function in the knee flexor and extensor muscles and earlier reports indicating reduced muscle strength may be explained by subjective weakness and difficulties completing tests due to musculoskeletal pain in earlier studies, which is common in patients with acromegaly even after long-term remission. In a study of 58 patients with controlled acromegaly, 90\% reported musculoskeletal pain, $84 \%$ had hip pain, and 30\% had knee osteoarthritis (18). The methodology used in our study with no movement of the hip may have reduced the element of pain, which may therefore have had less impact on our results than on the results of previous studies (i.e. walk tests and manual/clinical strength tests).

Interestingly, Walchan et al. (9) and da Silva Homem et al. (10) showed reduced muscle flexion and extension in patients with acromegaly compared to healthy matched controls tested by similar methods as in our study. However, there are notable differences in the patient groups studied, and in the treatment regimen of acromegaly. It appears that our patients at diagnosis were younger and healthier in general, but affected by higher hormone levels at diagnosis compared to the patients 
studied in the above publications. It is possible that with extensive disease duration and variable hormone control, arthropathies evolve that were not present in our patients at diagnosis and that might have impact on muscle strength and balance.

The mechanism of action of GH on skeletal muscle is thought to be both direct and indirect via IGF-I. The molecular pathways that lead to muscle hypertrophy by increased protein synthesis without alterations in proteolysis are well studied in both animal and human experiments (reviewed in (19)). It is also well documented that GH replacement of GH-deficient adults leads to increased muscle mass within a few months of treatment, although the effect on muscle strength is less clear or delayed $(20,21,22,23)$. Previous placebo-controlled trials could not show any effect of short-term GH treatment on muscle strength, although exercise performance and maximum oxygen consumption increased (21, 24, 25 ). Our group has previously showed an increase and normalization in isometric knee extensor and flexor strength after 2 years of treatment, which is much later than the effects seen on muscle volume, implying a nonlinear relationship between the effect on muscle size and function (13). In healthy young (26) and elderly (27) men, no increase in muscle strength could be shown over placebo after 3-4 months of $\mathrm{GH} /$ placebo treatment and exercise although body composition changed in the GH-treated subjects as expected. Effects of GH on muscle strength are therefore more complex than merely an effect of increased muscle volume.

Histological studies in patients with acromegaly have mainly found hypertrophy of type 1 muscle fibres and varying findings in type 2 fibres $(8,28,29)$. Type 1 fibres are the slow-twitch endurance resistant muscle fibres that rely on aerobic energy. In our study after long-term follow-up (median 11 years) from treatment, strength in isometric and concentric knee extension remained constant and comparable to the healthy reference population with a slight decrease in extension at high velocities (180\%) (Fig. 1A). This reduced muscle function at high speeds was accentuated when we tested for endurance with a significant increase of fatigue index. It could be speculated that the hypertrophy induced by long-standing excess of GH damages type 1 fibres and results in long-term loss of endurance. These findings are in line with Walchman et al. (9) and da Silva Homem et al. (10) that showed muscle weakness to be more pronounced at high velocities.

While concentric knee flexion remained stable and normal during the whole study period, we found a significant increase in isometric muscle strength for flexion at an angle of $60^{\circ}$ to about 1.5 times the predicted strength. This could not be explained by outliers such as men using testosterone replacement, or lack of the expected age-related decline in absolute muscle strength (data not shown). Age-related changes in muscle performance are thought to be brought upon by a process termed 'excitation-contraction uncoupling', where defects in the interaction between motor neuron and muscle fibre lead to reduced myoplasmatic peak $\mathrm{Ca}^{2+}$ concentrations after fibre activation (30). IGF-I plays an important role in normal excitation-contraction coupling as it regulates transcription of the dihydropyridine receptor that mediates the transduction of the electrical to mechanical signal at the sarcolemmal T-tubule by releasing intracellular $\mathrm{Ca}^{2+}$ upon depolarization (31). Over-expression of IGF-I in motor neurons of ageing mice inhibits the decline in specific force typical for ageing (32) and muscle-specific over-expression leads to preserved muscle force, prevents atrophy of type-2 fibres and maintains the regenerative capacity during ageing (33). Despite normal serum IGF-I levels at follow-up, half of our patients were dependent on medical treatment. Somatostatin analogues only succeed in normalizing IGF-I in about $60 \%$ of cases (34). It is possible that our patients at times had elevated IGF-I levels that could have counteracted the normal age-related decline in muscle function. This could affect isometric strength stronger than concentric action, as the maximum isometric force of a muscle is greater than the maximum force generated by concentric contraction (35).

At diagnosis, our patients had a reduced hand grip strength and endurance, which was normalized one year after treatment (Fig. 1B). One previous cross-sectional casecontrolled study could not find a difference in hand grip strength among 30 elderly patients with acromegaly (16 with uncontrolled disease) compared to controls (36). The discrepancy to our study may be due to the heterogeneous population in this previous study with patients with and without biochemical remission as well as using elderly patients. Hand grip strength reflects the combined action of the muscles of the arm and hand. It is a validated and widely used method associated with disease severity and nutritional state and outcome in a variety of diseases (37). Hand grip strength is also associated with total muscle mass in many patient populations $(38,39,40)$, although this could not be shown in our patients with acromegaly (data not shown). Carpal tunnel syndrome and swelling of the hand and fingers are common in active acromegaly. Four of our patients had carpal tunnel 
syndrome and one patient had ulnaris syndrome at diagnosis documented in their file. As nerve compression symptoms were not systematically evaluated in this study, it is possible that more patients were affected. This issue together with peripheral oedema may contribute to the reduced grip strength and is reversible upon treatment as body composition normalizes. Our finding that hand grip strength normalizes upon treatment is in agreement with the findings of Walchman et al. that found a correlation between hand grip strength and serum GH levels (9).

In conclusion and contrary to earlier observations, patients with acromegaly in this study did not suffer from proximal muscle weakness when quantitatively tested at diagnosis and during long-term follow-up. Hand grip strength on the other hand was reduced and normalized after treatment.

\section{Declaration of interest}

D S O has been a consultant for Novartis, Sandoz, Ipsen, and Pfizer. G J has been a consultant for AstraZeneca, Novo Nordisk and Shire, and has received lecture fees from Merck Serono, Novo Nordisk, Novartis, Otsuka, Pfizer and Shire. The other authors ( $L$ F, L-L N, B-Å B, K S S) declare they have no conflict of interest.

\section{Funding}

This research received an unrestricted grant from Novartis and was supported by the Swedish federal government under the ALF agreement on medical training and research. The sponsors did not take part in the design and conduct of the study, in the collection, management, analysis and interpretation of data, or in the writing and the decision to submit the manuscript.

\section{Acknowledgements}

The authors would like to express their gratitude to the staff at the Centre for Endocrinology and Metabolism at the Department of Endocrinology at Sahlgrenska University Hospital for their excellent collaboration. They would also like to thank Vibeke Malmros and her staff at the Department of Clinical Nutrition at Sahlgrenska University Hospital and emeritus professor Gunnar Grimby and the personnel of the rehabilitation laboratory at the Institute of Neuroscience and Physiology for their help with measurement of body composition and muscle testing, respectively.

\section{References}

1 Holdaway IM, Bolland MJ \& Gamble GD. A meta-analysis of the effect of lowering serum levels of GH and IGF-I on mortality in acromegaly. European Journal of Endocrinology 2008159 89-95. (doi:10.1530/EJE08-0267)

2 Lesen E, Granfeldt D, Houchard A, Dinet J, Berthon A, Olsson DS, Bjorholt I \& Johannsson G. Comorbidities, treatment patterns and cost-of-illness of acromegaly in Sweden: a register-linkage populationbased study. European Journal of Endocrinology 2017176 203-212. (doi:10.1530/EJE-16-0623)

3 Reid TJ, Jin Z, Shen W, Reyes-Vidal CM, Fernandez JC, Bruce JN, Kostadinov J, Post KD \& Freda PU. IGF-1 levels across the spectrum of normal to elevated in acromegaly: relationship to insulin sensitivity, markers of cardiovascular risk and body composition. Pituitary 2015 18 808-819. (doi:10.1007/s11102-015-0657-2)

4 Brummer RJ, Lonn L, Kvist H, Grangard U, Bengtsson BA \& Sjostrom L. Adipose tissue and muscle volume determination by computed tomography in acromegaly, before and 1 year after adenomectomy. European Journal of Clinical Investigation 1993 23 199-205. (doi:10.1111/j.1365-2362.1993.tb00762.x)

5 Bengtsson BA, Brummer RJ, Eden S \& Bosaeus I. Body composition in acromegaly. Clinical Endocrinology 198930 121-130. (doi:10.1111/j.1365-2265.1989.tb03733.x)

6 Bengtsson BA, Brummer RJ, Eden S, Bosaeus I \& Lindstedt G. Body composition in acromegaly: the effect of treatment. Clinical Endocrinology 198931 481-490. (doi:10.1111/j.1365-2265.1989. tb01272.x)

7 Pickett JB, Layzer RB, Levin SR, Scheider V, Campbell MJ \& Sumner AJ. Neuromuscular complications of acromegaly. Neurology 197525 638-645. (doi:10.1212/WNL.25.7.638)

8 Mastaglia FL, Barwich DD \& Hall R. Myopathy in acromegaly. Lancet 19702 907-909. (doi:10.1016/S0140-6736(70)92072-6)

9 Walchan EM, Guimarães FS, Soares MS, Kasuki L, Gadelha MR \& Lopes AJ. Parameters of knee isokinetic dynamometry in individuals with acromegaly: association with growth hormone levels and general fatigue Isokinetics and Exercise Science 201624 331-340. (doi:10.3233/ IES-160635)

10 da Silva Homem T, Guimaraes FS, Dos Santos Soares M, de Pinho LK, Gadelha MR \& Lopes AJ. Balance control and peripheral muscle function in aging: a comparison between individuals with acromegaly and healthy subjects. Journal of Aging and Physical Activity 201625 218-227. (doi.10.1123/japa.2016-0100)

11 Sunnerhagen KS, Hedberg M, Henning GB, Cider A \& Svantesson U. Muscle performance in an urban population sample of 40- to 79-yearold men and women. Scandinavian Journal of Rehabilitation Medicine 200032 159-167. (doi:10.1080/003655000750060904)

12 Bruce A, Andersson M, Arvidsson B \& Isaksson B. Body composition. Prediction of normal body potassium, body water and body fat in adults on the basis of body height, body weight and age. Scandinavian Journal of Clinical and Laboratory Investigation 198040 461-473. (doi:10.3109/00365518009101869)

13 Johannsson G, Grimby G, Sunnerhagen KS \& Bengtsson BA. Two years of growth hormone $(\mathrm{GH})$ treatment increase isometric and isokinetic muscle strength in GH-deficient adults. Journal of Clinical Endocrinology and Metabolism 199782 2877-2884. (doi:10.1210/ jc.82.9.2877)

14 Brummer RJ, Lonn L, Bengtsson BA, Kvist H, Bosaeus I \& Sjostrom L. Comparison of different body composition models in acromegaly. Growth Regulation 19966 191-200.

15 Freda PU, Shen W, Reyes-Vidal CM, Geer EB, Arias-Mendoza F, Gallagher D \& Heymsfield SB. Skeletal muscle mass in acromegaly assessed by magnetic resonance imaging and dual-photon x-ray absorptiometry. Journal of Clinical Endocrinology and Metabolism 2009 94 2880-2886. (doi:10.1210/jc.2009-0026)

16 Fosbol MO \& Zerahn B. Contemporary methods of body composition measurement. Clinical Physiology and Functional Imaging 201535 81-97. (doi:10.1111/cpf.12152)

17 Tominaga A, Arita K, Kurisu K, Uozumi T, Migita K, Eguchi K, IIda K, Kawamoto H \& Mizoue T. Effects of successful adenomectomy on body composition in acromegaly. Endocrine Journal 199845 335-342. (doi:10.1507/endocrj.45.335)

18 Miller A, Doll H, David J \& Wass J. Impact of musculoskeletal disease on quality of life in long-standing acromegaly. European Journal of Endocrinology 2008158 587-593. (doi:10.1530/EJE07-0838)

19 Woodhouse LJ, Mukherjee A, Shalet SM \& Ezzat S. The influence of growth hormone status on physical impairments, functional limitations, and health-related quality of life in adults. Endocrine Reviews 200627 287-317. (doi:10.1210/er.2004-0022) 
20 Cuneo RC, Salomon F, Wiles CM, Hesp R \& Sonksen PH. Growth hormone treatment in growth hormone-deficient adults. I. Effects on muscle mass and strength. Journal of Applied Physiology (1985) 199170 688-694.

21 Whitehead HM, Boreham C, McIlrath EM, Sheridan B, Kennedy L, Atkinson $\mathrm{AB}$ \& Hadden DR. Growth hormone treatment of adults with growth hormone deficiency: results of a 13-month placebo controlled cross-over study. Clinical Endocrinology 199236 45-52. (doi:10.1111/j.1365-2265.1992.tb02901.x)

22 Wallymahmed ME, Foy P, Shaw D, Hutcheon R, Edwards RH \& MacFarlane IA. Quality of life, body composition and muscle strength in adult growth hormone deficiency: the influence of growth hormone replacement therapy for up to 3 years. Clinical Endocrinology 199747 439-446. (doi:10.1046/j.13652265.1997.2801076.x)

23 Rodriguez-Arnao J, Jabbar A, Fulcher K, Besser GM \& Ross RJ. Effects of growth hormone replacement on physical performance and body composition in GH deficient adults. Clinical Endocrinology 199951 53-60. (doi:10.1046/j.1365-2265.1999.00737.x)

24 Woodhouse LJ, Asa SL, Thomas SG \& Ezzat S. Measures of submaximal aerobic performance evaluate and predict functional response to growth hormone $(\mathrm{GH})$ treatment in $\mathrm{GH}$-deficient adults. Journal of Clinical Endocrinology and Metabolism 199984 4570-4577. (doi:10.1210/jc.84.12.4570)

25 Jorgensen JO, Vahl N, Hansen TB, Thuesen L, Hagen C \& Christiansen JS. Growth hormone versus placebo treatment for one year in growth hormone deficient adults: increase in exercise capacity and normalization of body composition. Clinical Endocrinology 199645 681-688. (doi:10.1046/j.1365-2265.1996.8720883.x)

26 Yarasheski KE, Campbell JA, Smith K, Rennie MJ, Holloszy JO \& Bier DM. Effect of growth hormone and resistance exercise on muscle growth in young men. American Journal of Physiology 1992262 E261-E267.

27 Yarasheski KE, Zachwieja JJ, Campbell JA \& Bier DM. Effect of growth hormone and resistance exercise on muscle growth and strength in older men. American Journal of Physiology 1995268 E268-E276.

28 Nagulesparen M, Trickey R, Davies MJ \& Jenkins JS. Muscle changes in acromegaly. BMJ 19762 914-915. (doi:10.1136/bmj.2.6041.914)

29 Khaleeli AA, Levy RD, Edwards RH, McPhail G, Mills KR, Round JM \& Betteridge DJ. The neuromuscular features of acromegaly: a clinical and pathological study. Journal of Neurology, Neurosurgery, and Psychiatry 198447 1009-1015. (doi:10.1136/jnnp.47.9.1009)
30 Delbono O. Molecular mechanisms and therapeutics of the deficit in specific force in ageing skeletal muscle. Biogerontology 20023 265-270. (doi:10.1023/A:1020189627325)

31 Delbono O. Expression and regulation of excitation-contraction coupling proteins in aging skeletal muscle. Current Aging Science 2011 4 248-259. (doi:10.2174/1874609811104030248)

32 Payne AM, Zheng Z, Messi ML, Milligan CE, Gonzalez E \& Delbono O. Motor neurone targeting of IGF-1 prevents specific force decline in ageing mouse muscle. Journal of Physiology $2006 \mathbf{5 7 0} 283-294$. (doi:10.1113/jphysiol.2005.100032)

33 Musaro A, McCullagh K, Paul A, Houghton L, Dobrowolny G, Molinaro M, Barton ER, Sweeney HL \& Rosenthal N. Localized Igf-1 transgene expression sustains hypertrophy and regeneration in senescent skeletal muscle. Nature Genetics 200127 195-200. (doi:10.1038/84839)

34 Cozzi R, Attanasio R, Montini M, Pagani G, Lasio G, Lodrini S, Barausse M, Albizzi M, Dallabonzana D \& Pedroncelli AM. Four-year treatment with octreotide-long-acting repeatable in 110 acromegalic patients: predictive value of short-term results? Journal of Clinical Endocrinology and Metabolism 200388 3090-3098. (doi:10.1210/ jc.2003-030110)

35 Faulkner JA, Larkin LM, Claflin DR \& Brooks SV. Age-related changes in the structure and function of skeletal muscles. Clinical and Experimental Pharmacology and Physiology 200734 1091-1096. (doi:10.1111/j.1440-1681.2007.04752.x)

36 Hatipoglu E, Yuruyen M, Keskin E, Yavuzer H, Niyazoglu M, Doventas A, Erdincler DS, Beger T, Kadioglu P \& Gundogdu S. Acromegaly and aging: a comparative cross-sectional study. Growth Hormone and IGF Research 201525 47-52. (doi:10.1016/j.ghir.2014.12.003)

37 Norman K, Stobaus N, Gonzalez MC, Schulzke JD \& Pirlich M. Hand grip strength: outcome predictor and marker of nutritional status. Clinical Nutrition 201130 135-142. (doi:10.1016/j.clnu.2010.09.010)

38 Brodin E, Ljungman S, Hedberg M \& Sunnerhagen KS. Physical activity, muscle performance and quality of life in patients treated with chronic peritoneal dialysis. Scandinavian Journal of Urology and Nephrology 200135 71-78. (doi:10.1080/00365590151030886)

39 Windsor JA \& Hill GL. Grip strength: a measure of the proportion of protein loss in surgical patients. British Journal of Surgery 198875 880-882. (doi:10.1002/bjs.1800750917)

40 Norman K, Schutz T, Kemps M, Josef Lubke H, Lochs H \& Pirlich M. The Subjective Global Assessment reliably identifies malnutritionrelated muscle dysfunction. Clinical Nutrition 200524 143-150. (doi:10.1016/j.clnu.2004.08.007)

Received 11 February 2017

Revised version received 23 April 2017

Accepted 30 May 2017 